\title{
Dos Notas al Texto de La Araucana
}

\section{ERCILLA y GarctLASO}

Marcel Bataillon ha señalado dos textos americanos, un documento de 1535 de don Vasco de Quiroga, oidor de Méxica y obispo de Michoacán, y un párrafo de la Historia de las Indias de fray Bartolomé de Las Casas, que testimonian la crueldad de los conquistadores españoles que probaban el filo de sus espadas en los indígenas rendidos, y los ha relacionado con los versos séptimo y octavo del Soneto II de Garcilaso de la Vega:

$$
\begin{aligned}
& \text { para que sólo en mí fuese probado } \\
& \text { cuánto corta una espada en un rendido }
\end{aligned}
$$

Puede agregarse un eco seguro del texto de Garcilaso en La Araucana de don Alonso de Ercilla; en efecto, en el Canto VI de la Primera Parte (1569), Ercilla describe la crueldad con los vencidos en términos semejantes. En este caso, son los araucanos quienes ejercen la violencia sobre los españoles que trataban de huir en la derrota:

Flojos ya los caballos y encalmados

los bárbaros por pies los alcanzaban

y en los rendidos dueños derribados

la fuerza de los brazos ensayaban

(VI, 32, 1.4)

En consonancia con la casi mítica fortaleza que Ercilla atribuye a los indigenas de Chile, el texto aquí reemplaza la espada por los brazos de los enemigos $\mathrm{y}$, al mismo tiempo, ilustra más dramáticamente la debilidad

1 "Glosa americana al Soneto II de Garcilaso", Correo Erudito, 3, entrega 37, pp. 265-266; reproducido ahora en Varia lección de clásicos españoles (Madrid: Gredos, 1964), pp. 24-26. 
de los españoles cansados y heridos. En típica imagen ariostesca ${ }^{2}$ Ercilla se refiere a la sangre derramada de los españoles, tan abundante

$$
\begin{aligned}
& \text {...... que el verde prado } \\
& \text { quedaba de su rastro colorado }
\end{aligned}
$$

$$
\text { (VI, 31, 7-8) }
$$

Por cierto, no les faltan espadas a los araucanos, y Ercilla las menciona empleadas contra los españoles que aún combatían o, para acentuar el efecto de la escena, contra las indefensas mujeres (estrofas 35 y 36).

Ercilla, naturalmente, conocía muy bien la poesía de Garcilaso y a él sin duda se refiere en su propio poema $(\mathrm{XV}, 2,5)$ según ya señalaba Menéndez y Pelayo. ${ }^{3}$ Nos importa advertir aquí la comunidad expresiva de la lengua de la poesía lírica y de la épica, y sus relaciones con la documentación histórica. No debe sorprender que los textos aducidos por Bataillon y el de Ercilla se refieran precisamente a los dos aspectos opuestos del mismo conflicto con la misma fórmula literaria; en un mundo en que la guerra aún conservaba rastros de un acto heroico, por lo menos para la literatura, el reproche de crueldad y cobardía a los que probaban fuerzas o filos en el enemigo vencido, debió ser lugar común de la ética guerrera, que despreciaba un crimen indigno del valor del soldado. El nada infrecuente paso de la lengua de la guerra al de la poesía amorosa se verifica en Garcilaso, de donde tomó Ercilla la expresión, ya jerarquizada literariamente, y la aplicó a su elaborada retórica bélica, en una escena de la que fue testigo presencial ${ }^{4}$ y en la que la expresividad equilibra el dato histórico de segunda mano; el tercer aspecto del uso de la frase en cuestión se cumple, como documento, en los testimonios que recoge $\mathrm{Ba}$ taillon.

\section{ERCILLA Y BORGES}

La segunda estrofa del "Poema conjetural" de Jorge Luis Borges ${ }^{5}$ se inicia con una comparación que relaciona al doctor Francisco Laprida, narrador del poema, con un personaje de la Divina Comedia:

2 Cf. Antonio Vilanova, Las fuentes del "Polifemo" de Góngora (Madrid: RFE, Anejo LXVI, 1957), I, p. 23.

3 Cf. Historia de la poesia Hispano-Americana (Madrid, 1913), II, p. 227.

4 La experiencia personal de la lucha en Chile recién comienza en el Canto XII, estr. 69. Cf. Juan B. Avalle-Arce, "El poeta en su poema (El caso Ercilla)" Revista de Occidente, XCV (1971), 152-169.

5 Jorge Luis Borges, Poemas (1922-1943) (Buenos Aires: Losada, 1943). 
Como aquel capitán del Purgatorio que, huyendo a pie y ensangrentando el llano, fue cegado y tumbado por la muerte donde un oscuro río pierde el nombre.

Característicamente, Borges no da el nombre del personaje y prefiere a la identidad civil e histórica, la más perdurable de las palabras que Dante pone en boca del capitán Buonconte de Montefeltro. En efecto, los versos de Borges son traducción libre del texto de Purgatorio, Canto V, 94-100:
Oh, rispuos'elli a piè del Casentino traversa un'acqua c'ha nome l'Archiano, che sovra l'Ermo nasce in Apennino.
Là 've 'l vocabol suo diventa vano, arriva' io forato nella gola, fuggendo a piede e 'nsanguinando il piano. Quivi perdei la vista e la parola;

Este uso de otros textos literarios es procedimiento bastante frecuente en Borges y, en general, puede ser menos explícito y hasta engañoso, como señalaba María Rosa Lida de Malkiel. ${ }^{6}$ Pero los versos del Purgatorio ya habían sido incorporados a la poesía española por Ercilla; en la Primera Parte de La Araucana traduce también el verso 97 de Dante en un pasaje que describe la derrota y huida de los españoles en la cuesta de Andalicán:
Los nuestros, del temor más aguijados, al entrar de la noche se hallaron en la estrema ribera de Biobío adonde pierde el nombre y ser de río

$$
\text { (VII, 3, 4-8) }
$$

La comparación de los dos textos sería relativamente inútil si se limitara a comprobar una fuente común, harto explícita en Borges y nada sorprendente en un lector de Dante como lo fue Ercilla. ${ }^{7}$ Pero parece haber algo más que simple coincidencia de fuente; en la Tercera Parte

6 "Contribución al estudio de las fuentes de Jorge Luis Borges" Sur, 213-214, (1952) 50-57; también Sylvia Molloy "Borges y la distancia literaria"' Sur, 318, (1969) 26-37.

7 Por ejemplo, en el Canto XVI, 10 de La Araucana, la referencia a Amiclas proviene de Paratiso XI, 63 y también Convivio IV, 13. 
de su poema (1589), Ercilla recuerda un momento dramático de su propia vida en América, cuando fue condenado a muerte por el gobernador don García Hurtado de Mendoza e indultado a último momento

que estuve en el tapete, ya entregado al agudo cuchillo la garganta

(XXXVI, 33, 3-4)

A su vez, el poema de Borges concluye con estos dos versos

ya el duro hierro me raja el pecho, el intimo cuchillo en la garganta.

Lo que sorprende en los dos textos es la similaridad expresiva de dos situaciones semejantes. Ercilla, creador, espectador y actor de una épica que equilibra el respeto a la convención literaria con la aventura autobiográfica $^{8}$ se refiere al momento anterior al que iba a ser el de su vivencia última de condenado a muerte por "la celeridad del juez" y el "inorme delito exagerado"; su "yo" es indudable no solamente por su calidad histórica de testigo y protagonista sino también por la realidad de su calidad de narrador sobreviviente; así crea en el lector el sobresalto ante la situación revivida en el documento escrito.

En Borges, en cambio, la misma experiencia está completamente rehecha, pues la primera persona es "ficticia" como lo propone el título del poema, en homenaje a la irreversible verdad histórica. La emoción en el lector ya no la puede suscitar la mera existencia del texto y por esto recurre Borges al epígrafe explicatorio que prepara una lectura justa:

El doctor Francisco Laprida, asesinado el día 22 de septiembre de 1829 por los montoneros de Aldao, piensa antes de morir:

En ambos textos está viva la impresión semejante de dos destinos a punto de ser cambiados; Ercilla poco después del episodio deja para siempre Chile y vuelve a España (estrofas 34 a 40 del Canto XXXVI) para ser el gran poeta épico del siglo xvi. Laprida, nacido para ser un hombre

- Cf. Carlos Albarracin Sarmiento, "Pronombres de primera persona y tipos de narrador en La Araucana" BRAE, 46 (1966) pp. 297.320 y también Lía Schwartz Lerner "Tradición literaria y heroínas indias en La Araucana" RI, 36 (1972) pp, 615-625. 
de sentencias, de libros, de dictámenes, a cielo abierto yaceré entre ciénagas; pero me endiosa el pecho inexplicable un júbilo secreto. Al fin me encuentro con mi destino sudamericano.

Esta disparidad final al nivel de los acontecimientos explica el cambio del epíteto de Ercilla en el cultismo de sentido usado por Borges; mientras que en el pasaje de La Araucana el "duro hierro" quedará como siniestra amenaza, en el "Poema conjetural" el adjetivo sugiere el momento en que el cuchillo penetra la carne del narrador, pues en el texto, intimo está usado en su acepción derivada del valor superlativo latino "lo que está más adentro, lo más interior"; por lo demás, éste parece haber sido el uso más frecuente en las primeras apariciones de la palabra en español. Ya registra Autoridades hacia 1580, en fray Luis de Granada, la expresión fija lo más intimo de las entrañas; es la misma expresión que aparece en Cervantes por lo menos tres veces, quien, además, emplea la palabra en el hoy común uso traslaticio de origen latino "íntimo amigo" en la Galatea. ${ }^{\circ}$ Estos ejercicios semánticos no son infrecuentes en Borges y él mismo ha señalado "goce honesto y justiciero" del uso de las palabras en su valor etimológico. ${ }^{10}$

También es frecuente en Borges la reiteración de situaciones similares en contextos diferentes. Veintidós años después del "poema conjetural", en la "Milonga de Jacinto Chiclana","11 el cuchillo que mata a Chiclana es el pretexto para imaginar, nuevamente, el pensamiento final de cada hombre, que sigue intrigando a Borges:

Acaso en aquel momento en que le entraba la herida pensó que a un varón le cuadra no demorar la partida.

ISAÍAS LERNER

H.H. Lebman College (CUNY)

- Carlos Pernández Gómez, Vocabulario de Cervantes (Madrid: RAE, 1962).

10 Cf. Ana Maria Barrenechea, La expresión do la irrealidad en la obra de Borges (Buenos Aires: Paidós, 1967), p. 226.

11 Jorge Luis Borges, Para las siete cuerdas (Buenos Aires, 1965). 
